\title{
The variability of particle backscattering coefficient in an oligo-to-hypertrophic cascading reservoir system: implications to TSM bio-optical model development
}

\author{
Enner Alcântara ${ }^{1}$ (D) Fernanda Watanabe $^{1} \cdot$ Nariane Bernardo $^{1} \cdot$ Thanan Rodrigues $^{1}$
}

Received: 25 May 2016/Accepted: 25 May 2016/Published online: 6 June 2016

(C) Springer International Publishing Switzerland 2016

\begin{abstract}
The particle backscattering coefficient $\left(b_{b p}\right)$ has been obtained either by equipment or semi-analytically based on relations between $b_{b p}$ and the remote sensing reflectance $\left(R_{r s}\right)$. Correlation between $b_{b p}$ and $R_{r s}$ can be significantly high allowing the development of bio-optical model to estimate the total suspended matter concentration [TSM] on water surface from satellite images. The development of such model to monitor cascading reservoir systems can be challenging since this type of water resources changes their biogeochemical composition from upstream to downstream; the water in such system can range from hypertrophic to oligotrophic state. The scientific question raised in this letter is that: in an oligo-tohypertrophic water system the models based on $b_{b p}$ will keep their good agreement or the influence of organic matter (e.g. chlorophyll- $a$ ) can affect this relationship? The aim of this letter was to analyze the $b_{b p}$ variability in a cascading reservoir system and search for empirical models that can capture the relationship between the $b_{b p}$ and [TSM]. The results showed that there are not only differences in the biogeochemical concentrations but also in the $b_{b p}$ from upstream to downstream. In addition there is an influence of chlorophyll- $a$ concentration [Chl- $a$ ] on the relationship between $b_{b p}$ and [TSM] which prevents the bio-optical model development.
\end{abstract}

Keywords Quasi-analytical algorithm - Case-2 waters . Particle backscattering · Trophic state

Enner Alcântara

enner@fct.unesp.br

1 Department of Cartography, São Paulo State University-Unesp, Presidente Prudente, São Paulo, Brazil

\section{Introduction}

Scattering and backscattering are important inherent optical properties (IOPs) of water. The scattering coefficient, $b\left(\mathrm{~m}^{-1}\right)$, refers to the fractional part of the incident power that is scattered out of the beam in all directions and can be expressed by the beam attenuation, $c$, minus the absorption, $a\left(\mathrm{~m}^{-1}\right)$. The backscattering coefficient, $b_{b}$, refers to the portion of the scattering of electromagnetic radiation in the backward direction that is deflected through a scattering angle higher than $90^{\circ}$. The $b_{b}\left(\mathrm{~m}^{-1}\right)$ is directly related to the signal exiting the water column, the so-called water-leaving radiance, and then the knowledge of $b_{b}$ is of primary importance for remote sensing applications (Boss and Pegau 2001).

The particle backscattering, $b_{b p}\left(\mathrm{~m}^{-1}\right)$, fraction of the total $b_{b}$ that is not due to the water molecules, is an important IOP. It describes not only how light returned to the water surface and thus forms the signal collected by sensors, but also has scientific implications and practical applications in optical remote sensing, as the light backscattered from various seawater constituents provides the possibility to derive information on the particulate populations under investigation (Shanmugam et al. 2011)). Researchers have been conducted on the $b$ and $b_{b p}$ mainly focused on the open ocean, since 1970s (Pak et al. 1970; Stramski et al. 2001; McKee and Cunningham 2006; Antoine et al. 2011). However, the research related to the backscattering properties of inland waters, especially in Brazilian hydroelectric reservoirs, is incipient (Alcântara et al. 2016).

Remote sensing methods to retrieve $b_{b p}$ are based on its relationship to $R_{r s}$ and can be empirical, semi-empirical, semi-analytical or analytical (Lee and Huot 2014). The $b_{b p}$ depends at first order on the particulate concentration and at second order on the chemical composition, particle size distribution (PSD), and structure of the bulk particulate 
matter (Stramski et al. 2004). The fraction of $b_{b p}$ affects the ocean color, determined by the relative contribution of living and nonliving particles (such as inorganic minerals, phytoplankton, and organic detritus) (Gordon et al. 1975). According to (Latha et al. 2013) many questions are still unsolved concerning the variability and controls on $b_{b p}$ and one way to progressively answer these questions is to analyze more concurrent in situ measurements of $b_{b p}$ and in-water constituents and their concentrations such as nonalgal particles, sediment types, chlorophyll, since IOPs are directly related to in-water constituents.

The scientific question raised in this letter is that: in an oligo-to-hypertrophic water system the models based on $b_{b p}$ will keep their good agreement or the influence of the organic matter (e.g. chlorophyll- $a$ ) can affect this relationship? The aims of this letter were (1) to analyze the $b_{b p}$ variability in a cascading reservoir system; (2) search for an empirical model that captures the relationship between $b_{b p}$ and [TSM], (3) identify the influence of the [Chl-a] on the bio-optical model development using the $b_{b p}$ as reference and (4) summarize the limitations and challenges in estimating the $b_{b p}$ from satellite images in tropical inland waters.

\section{Materials ANd Methods}

\section{Study Area}

The Barra Bonita (BB) and Nova Avanhandava (Nav) reservoirs (Fig. 1) are placed in the middle and lower courses of the Tietê River, São Paulo State, Brazil, respectively. The BB reservoir $\left(22^{\circ} 31^{\prime} 10^{\prime \prime} \mathrm{S}, 48^{\circ} 32^{\prime} 3^{\prime \prime} \mathrm{W}\right)$ is a storage system and began its operation in 1963 flooding an area of $310 \mathrm{~km}^{2}$, with $480 \mathrm{~m}$ of dam length and 90.3 days of average residence time (Soares and Mozeto 2006), being formed from the damming of Tietê and Piracicaba Rivers. Nav reservoir $\left(21^{\circ} 7^{\prime} 1^{\prime \prime} \mathrm{S}, 50^{\circ} 12^{\prime} 6^{\prime \prime} \mathrm{W}\right)$ is a run-of-river reservoir and was created in 1982, flooding an area of $210 \mathrm{~km}^{2}$ (at its maximum quota), with a dam length of $2038 \mathrm{~m}$ and mean residence time of the water around 46 days (Barbosa et al. 1999).

According to Padisák et al. (2000) the cascading reservoirs play an important role not only in providing services but also function as effective storing agents of considerable loads of nutrients, particularly at the upper-middle Tietê, contributing to the better water quality downstream of the cascade.

\section{Field campaign}

Two field campaigns were conducted in the end of the dry season in both BB and Nav reservoirs. In the BB reservoir, the field survey was accomplished in 13-16 October 2014
(Austral spring). In the Nav reservoir, the field campaigns occurred in 23-26 September 2014. A total of 18 samples were taken in BB and 19 samples in Nav.

\section{Water sampling processing}

Water samples were collected at each sampling spot and filtered through a glass fiber filter GF/F Whatman, $47 \mathrm{~mm}$ diameter and $0.7 \mu \mathrm{m}$ pore size, to estimate the Chl- $a$ concentration $\left(\mu \mathrm{g}^{-1}\right)$ in laboratory (Golterman 1975). To estimate TSM ( $\left.\mathrm{mg} \mathrm{l}^{-1}\right)$, water samples were also filtered through a glass fiber filter GF/F Whatman $(47 \mathrm{~mm}$ diameter and $0.7 \mu \mathrm{m}$ pore size) and stored frozen in the dark (APHA 1998).

\section{Volume scattering function and $b_{b}$}

The $b_{b}$ was measured using the ECO-BB9 equipment. ECO-BB9 acquires measurements at nine wavelengths centered at 412, 440, 488, 510, 532, 595, 650, 676 and $715 \mathrm{~nm}$ (WET Labs, Inc. 2013). ECO-BB9 measures the volume scattering function, $\beta\left(\mathrm{m}^{-1} \mathrm{sr}^{-1}\right)$, around $117^{\circ}$ and is assumed that loss of photons due to scattering is negligible and only loss by absorption should be accounted for and corrected according to:

$\beta_{\text {correction }}=\left(170^{\circ}\right)=\beta_{\text {measured }}\left(170^{\circ}\right) \exp (0.0391 a)$

where $\beta_{\text {correction }}$ is the total volume scattering function, $\beta_{\text {measured }}$ is the raw calculated total volume scattering function, and $a$ is the corresponding absorption coefficient that can be measured using the WET Labs AC-S device.

The volume scattering function of particulates $\left(\beta_{p}\right)$ can be obtained by subtracting the volume scattering of water $\left(\beta_{\text {water }}\right)$ from the $\beta_{\text {correction }}$ as follows:

$\beta_{p}=\left(170^{\circ}\right)=\beta_{\text {correction }}\left(170^{\circ}\right)-\beta_{\text {water }}\left(170^{\circ}\right)$

Using $\beta_{p}$ the $b_{b p}$ is determined as:

$b_{b p}=2 \pi \chi \beta_{p}\left(117^{\circ}\right)$

From measurements of $\beta$ with high angular resolution in a diversity of water types (Boss and Pegau 2001) determined $\chi$ to be 1.1. This factor estimates $b_{b p}$ with an estimated uncertainty of $4 \%$. The conversion can be used for $\beta\left(117^{\circ}\right)$ measurements made at any visible wavelength. To compute the $b_{b}$ the backscattering from pure water $\left(b_{b w}\right)$ needs to be added to $b_{b p}$ (Morel 1974).

$b_{b}(\lambda)=b_{b p}(\lambda)+b_{b w}(\lambda)$

\section{Data interpolation}

The [TSM], [Chl-a] and $b_{b p}$ were interpolated using the Ordinary Kriging (OK) method (Isaaks and Srivastava 

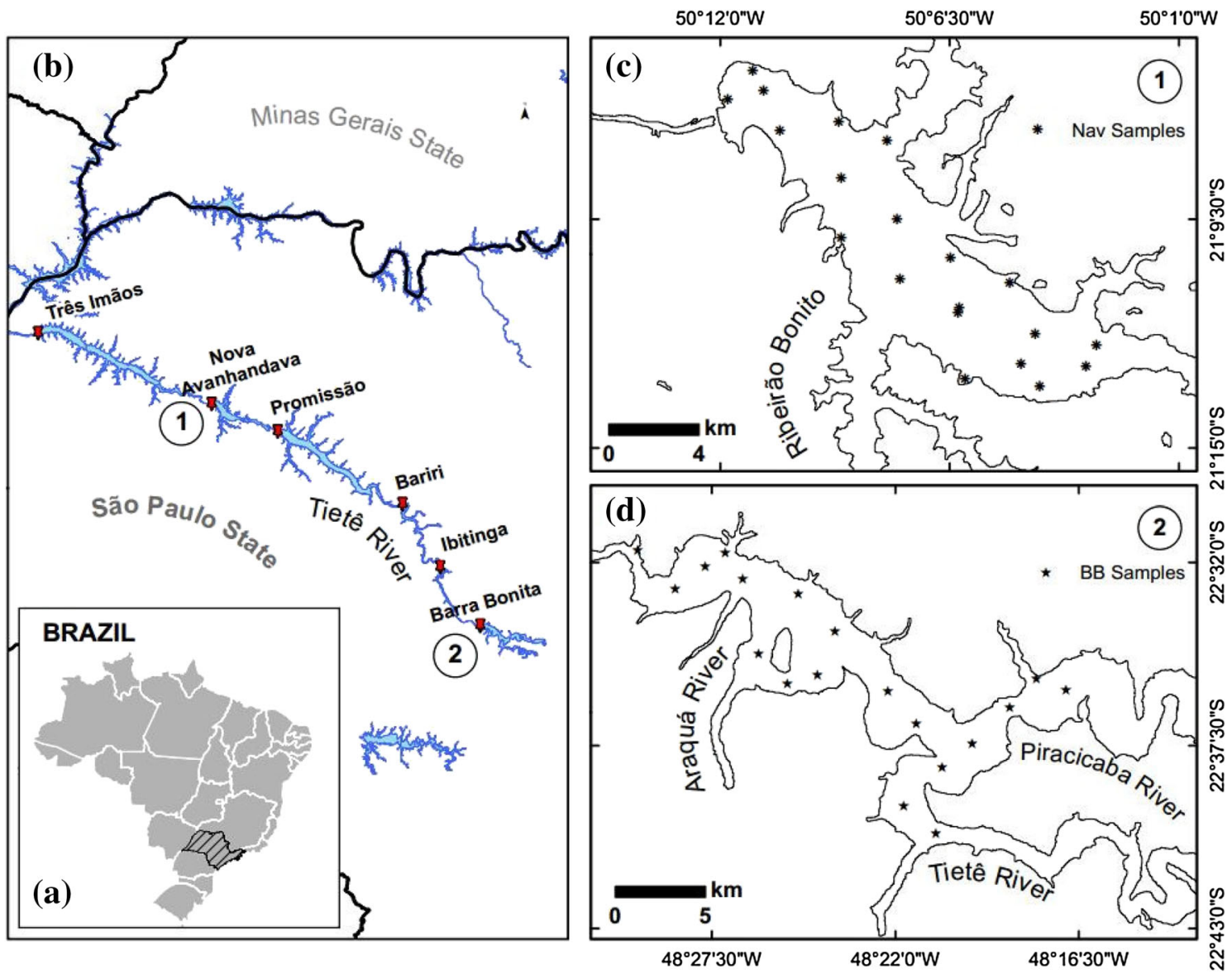

Fig. 1 Study area: a location of São Paulo State in Brazil, b Tietê River and the reservoirs location, c samples location in Nav and d in BB reservoirs. The numbers 1 and 2 represents the location of Nav and BB reservoirs, respectively

1989). The semivariograms were fitted testing several theoretical models (spherical, exponential, Gaussian, linear and power) and using the weighted least square method. The theoretical model that gave minimum standard error was chosen for further analysis. In this case, the fitted model was based on the Gaussian model. The adjustment on the Gaussian model suggests the existence of smooth spatial variance pattern at the study site (Burrough and Mcdonnell 1998).

\section{Results and discussions}

\section{Descriptive statistics of water quality parameters and $b_{b p}$ at $440 \mathrm{~nm}$}

The statistics of selected water quality parameters and optical data in both reservoirs are shown in Table 1.

The trophic state (TSI) classification approach proposed by Carlson (1977) and adapted for the tropical inland waters in Brazil (Lamparelli 2008) was used and according to this author we can estimate the TSI of Nav and BB reservoir using the following equation:

$$
\begin{aligned}
\operatorname{TSI}(C h l-a)= & 10 \times\{6-[(0.92-0.34 \\
& \times(\ln C h l-a)) / \ln 2]\}
\end{aligned}
$$

The TSI classification for Nav reservoir ranged from mesotrophic to eutrophic and for BB reservoir as hypertrophic. The classification obtained in this work for BB reservoir is corroborated by Watanabe et al. (2015). According to Alcântara et al. (2016), Nav reservoir can also be classified as oligotrophic if the Chl- $a$ concentration from the beginning of the dry season is considered (Austral Autumn). The next step was to calculate the $b_{b p}$ for Nav and $\mathrm{BB}$ reservoirs from $\beta$.

\section{Particle backscattering coefficient}

The Fig. 2 shows the $b_{b p}$ variability for Nav (a) and BB (b) reservoirs. The $b_{b p}$ at $440 \mathrm{~nm}\left(b_{b p 440}\right)$ values are slightly higher in Nav than in BB reservoir; only one sample in Nav reservoir was higher than $0.300 \mathrm{~m}^{-1}$. This 
Table 1 Water quality parameters and the $b_{b p}$ at $440 \mathrm{~nm}\left(b_{\mathrm{bp} 440}\right)$ descriptive statistics (SD is the standard deviation) for measurements taken from Nav and BB reservoirs. This wavelength was selected because is widely accepted and used as reference to study the optically active components present into the water

\begin{tabular}{llcl}
\hline & Chl- $a\left(\mu \mathrm{g}^{-1}\right)$ & TSM $\left(\mathrm{mg} \mathrm{l}^{-1}\right)$ & $b_{b p 440}\left(\mathrm{~m}^{-1}\right)$ \\
\hline Nav & & & \\
Min & 3.41 & 0.50 & 0.024 \\
Max & 20.48 & 10.00 & 0.340 \\
Mean & 8.73 & 1.45 & 0.057 \\
SD & \pm 4.17 & 2.03 & 0.071 \\
BB & & & \\
Min & 263.20 & 10.80 & 0.029 \\
Max & 797.80 & 32.80 & 0.067 \\
Mean & 428.70 & 20.80 & 0.042 \\
SD & \pm 154.50 & 4.90 & 0.009 \\
\hline
\end{tabular}

sample is near to a sand extraction area and thus the soil is easily carried in the water column increasing the turbidity. These results also showed that the $b_{b p 440}$ decreases with increasing wavelength. The [TSM], [Chl-a] and $b_{b p 440}$ were interpolated in order to show the spatial distribution.

\section{Water quality parameters and $b_{b p}$ variability}

The [TSM] distribution in Nav reservoir (Fig. 3a) was more homogeneously distributed than in $\mathrm{BB}$ reservoir (Fig. 3d) and as expected (from Table 1) the [TSM] in BB was 24 times higher than in Nav reservoir. The higher [TSM] values in Nav were concentrated in the east portion of the reservoir while in BB the [TSM] was predominant in the west portion.

The [Chl- $a$ ] maps shows that BB reservoir (Fig. 3e) was more homogeneous and presented values higher than in Nav reservoir (Fig. 3b). The [Chl-a] in BB was 61 times higher than in Nav reservoir. The $b_{b p 440}$ maps in Nav reservoir showed spots more delineated (Fig. 3c) with the lowest values occurring in the center of the water body and the highest values in the littoral zone. The spot with the highest $b_{b p 440}$ was more dominated by [TSM] than [Chl- $a$ ] in the upper side of the reservoir the contrary was seen in the down side, as can be observed in Fig. $3 \mathrm{a}$, b. The $b_{b p 440}$ for $\mathrm{BB}$ reservoir (Fig. 3f) was basically divided into two portions, the upper side with the highest values and the down side with the lowest values. This pattern coincides with the [TSM] map (Fig. 3d), since the highest [TSM] was observed for the upper side.

The next step was to analyze the relationship between $b_{b p 440}$ and [TSM], and the relationship between [TSM] and $[\mathrm{Chl}-a]$. This was done using simple regression models.

\section{Relationship between $b_{b p 440}$ and TSM concentration}

There was a very high correlation between [TSM] and $b_{b p 440}$ for Nav reservoir with a coefficient of determination $\left(\mathrm{R}^{2}\right.$ ) of 0.976 (Fig. 4a). Nav reservoir is an oligotrophic environment with very low [TSM] showing no correlation with [Chl-a] (Fig. 4b). In Nav the mean ratio between [TSM] and [Chl- $a$ ] was 0.26 which showed the dominance of inorganic fraction over the [TSM]; the rule broke down with the sample presenting [TSM] of $10 \mathrm{mg} \mathrm{l}^{-1}$, where the organic fraction dominated.

No relationship between [TSM] and $b_{b p 440}$ was observed for $\mathrm{BB}$ reservoir $\left(\mathrm{R}^{2}=0.0003\right.$, Fig. $\left.4 \mathrm{c}\right)$, on the other hand a weak relationship between [TSM] and [Chl- $a$ ] was observed $\left(\mathrm{R}^{2}=0.3884\right.$, Fig. $\left.4 \mathrm{~d}\right)$. The mean ratio between [TSM] and [Chl- $a$ ] was 0.055 which means that there was a dominance of organic fraction over the [TSM] in BB reservoir. Since the Chl- $a$ concentration was up to $713 \mu \mathrm{g}^{-1}$, the influence of the phytoplankton cells in the [TSM] was very high.

The lack of correlation between the $b_{b p 440}$ and the [Chla] can be attributed partially to the package affect. The package effect is a common physiological strategy for large phytoplankton species, such as diatoms and reduces the absorption spectra (Bricaud et al. 1995). These authors
Fig. $2 b_{b p}$ measured in Nav (a) and $\mathrm{BB}$ (b) reservoirs using the ECO-BB9 equipment

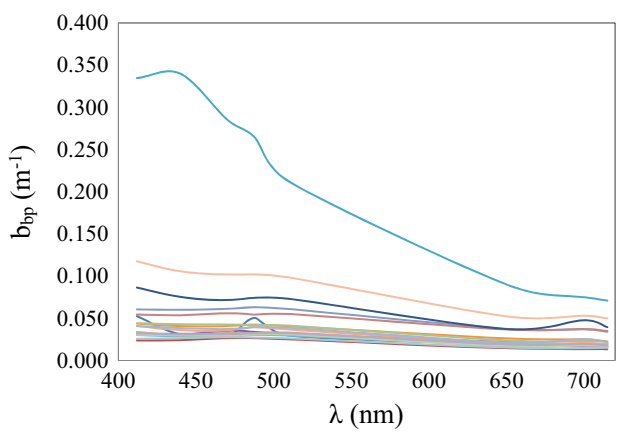

(a)

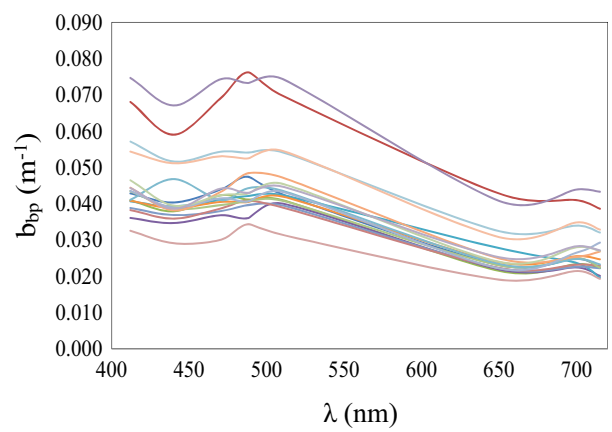

(b) 


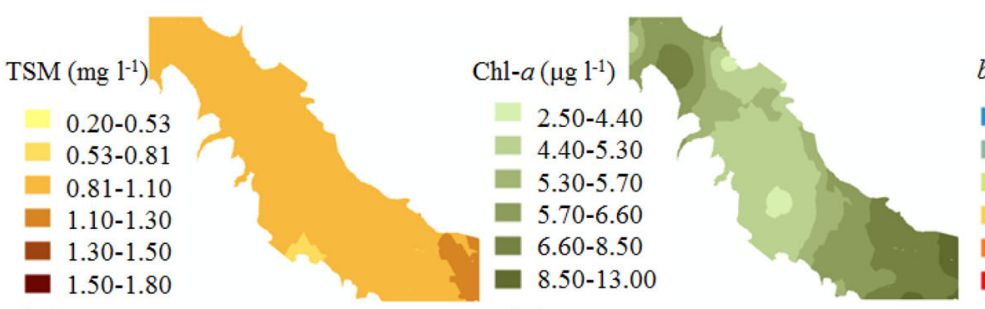

(a)

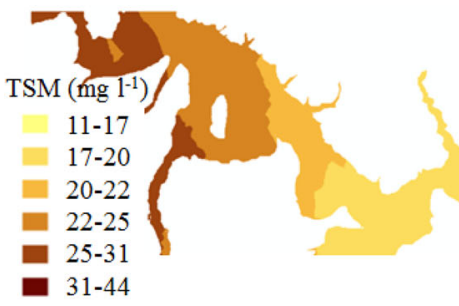

(d) (b)

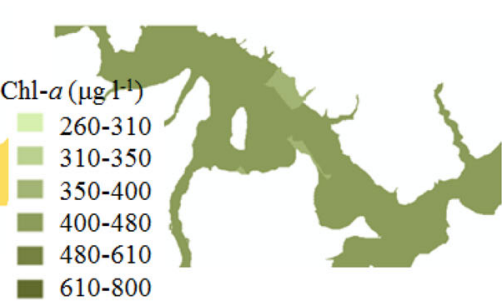

(e)

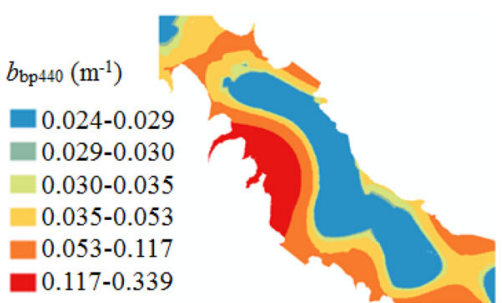

(c)

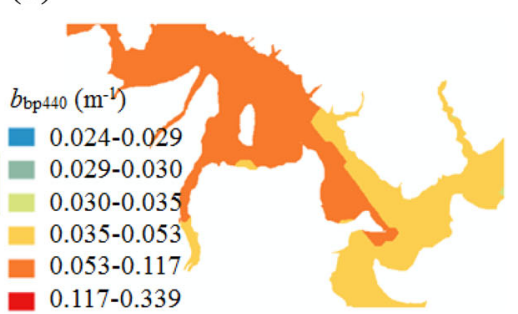

(f)

Fig. 3 Interpolated data using OK method: a [TSM], b [Chl- $a$ ] concentration, c $b_{b p 440}$ for Nav reservoir and $\mathbf{d}[\mathrm{TSM}], \mathbf{e}[\mathrm{Chl}-a]$, f $b_{b p 440}$ for BB reservoir

Fig. 4 Relationship between [TSM] and $b_{b p 440}$ in Nav (a) and $\mathrm{BB}$ (c) reservoirs and the relationship between the [TSM] and $[$ Chl- $a]$ in Nav (b) and BB (d) reservoirs

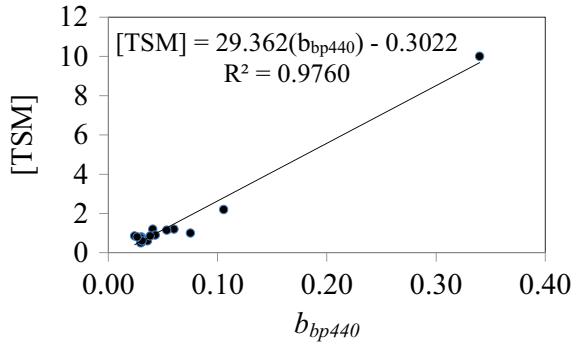

(a)

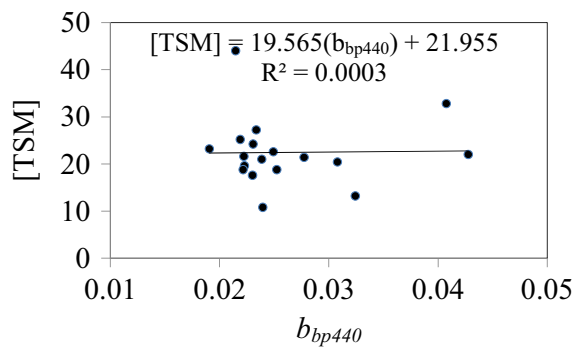

(c)

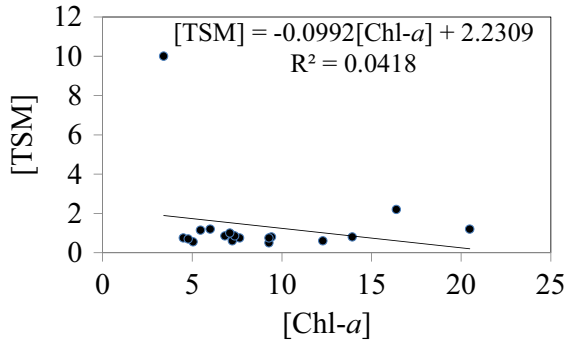

(b)

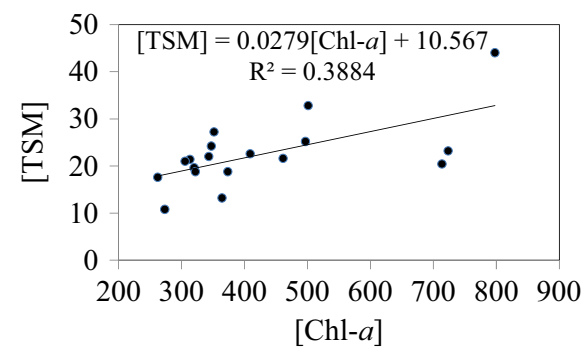

(d) discovered that the chlorophyll- $a$ specific absorption coefficient $a_{\text {phy }}^{*}$ decreases with increasing [Chl- $a$ ] at 412, 443 and $490 \mathrm{~nm}$ and is lower at $675 \mathrm{~nm}$. This inverse relationship was also reported in previous studies (Le et al. 2009a) and may be explained by the fact that an increase in [Chl- $a$ ] lead to an increase in the concentration of intracellular pigment or in cell volume rather than in cell number, resulting in an absorption efficiency loss in the package effect. The phytoplankton backscattering efficiency tends to be higher in blue than in red wavelength (Brewin et al. 2012), but can be masked due to the package effect.
Some authors have showed that $b_{b p}$ coefficient is highly correlated with TSM concentration (Wu et al. 2011). Lobo et al. (2014) investigated the relationship between $b_{b p}$ and [TSM] in a controlled laboratory setting, and their primary results revealed a $R^{2}=0.99$ for wavelengths at $470 \mathrm{~nm}$ and $532 \mathrm{~nm}$ and $R^{2}=0.97$ at $660 \mathrm{~nm}$. These results suggest that $b_{b p}$ can be used to estimate [TSM] in aquatic systems using remotely sensed images. The observed agreement between $b_{b p}$ and [TSM] so far was based on field or laboratory measurements, but the spatiotemporal monitoring of [TSM] will only be possible if this 
relationship holds true to be applied to a remotely sensed imagery.

\section{Challenges to estimate [TSM] from $b_{b p}$}

The main challenge in using $b_{b p}$ to estimate [TSM] from satellite images is to parameterize a model to estimate $b_{b p}$ from $R_{r s}$. Methods to remotely retrieve the optical properties are been under investigation for several decades. One of these methods is the quasi-analytical algorithm (QAA), which was originally developed by (Lee et al. 2002)). The QAA is a model that derives IOPs, in particular, the spectral coefficients of $a(\lambda)$ and $b_{\mathrm{b}}(\lambda)$, from $R_{\mathrm{rs}}(\lambda)$. The QAA algorithm is based on the relationship between $r_{\mathrm{rs}}$ (just below water surface remote sensing reflectance) and the IOPs of the water derived from the radiative transfer equation (RTE). The flow of QAA (version 5) to obtain the spectral $b_{b p}(\lambda)$ is show in Table 2 .

The QAA has been applied successfully in ocean water but, the applications to inland complex waters has proven that the algorithm fail mainly due to: (1) the estimation of the total absorption at a reference wavelength, $a\left(\lambda_{0}\right)$ that was empirically derived from synthetic dataset (step 2 in Table 2); and (2) the estimation of $Y$ (step 4 in Table 2), which was originally and empirically derived using samples collected in open ocean and coastal areas that can be different from inland waters (Yang et al. 2013). Besides, the reference wavelength $\left(\lambda_{0}\right)$ needs to be shifted from $555 \mathrm{~nm}$ to longer wavelengths, such as 753 (Yang et al. 2013) or $780 \mathrm{~nm}$ (Le et al. 2009b).

Watanabe (2016) parameterize and calibrate a QAA for BB reservoir and found that the wavelength of reference that provided the IOPs with the lowest error was $709 \mathrm{~nm}$. The main limitation of this wavelength is the lack of orbital sensors that operates in this spectral region. The Moderate resolution imaging spectroradiometer (MODIS) has 36 spectral bands, but the nearest spectral band of $709 \mathrm{~nm}$ is the band 14 $(678 \mathrm{~nm})$; and the spatial resolution is also a problem for cascading reservoir systems due to the $1 \mathrm{~km}$ spatial resolution. The Operational Land Imager (OLI) onboard of Landsat-8 has 9 spectral bands, with band $4(655 \mathrm{~nm})$.
The Ocean and Land Colour Instrument (OLCI) onboard Sentinel-3 has 21 spectral bands with the band 11 with central wavelength at $708.75 \mathrm{~nm}$. Therefore, the OLCI images will be very helpful to estimate the IOPs from satellite images support the parameterization of bio-optical models in order to estimate the COAs. The Sentinel-3 was launched in 16 February 2016 but until now the cascading system of Tietê River has not yet been imaged. Once OLCI images become available for our study area, the QAA model parameterized according to Watanabe (2016) will be used for COAs monitoring in a cascading system becoming operational.

Another method developed to estimate the $b_{b p}$ was presented by Tiwari and Shanmugam (2013) and was based on the diffuse attenuation coefficient $\left(k_{d}\right)$. In this work, these authors used two wavelengths of reference, 530 and $555 \mathrm{~nm}$, to relate the $k_{d}$ at $490 \mathrm{~nm}\left(k_{d 490}\right)$ and the $b_{b p}$. Up to now this method has not been applied to inland waters in Brazil, but seems that the same problem of QAA will be encountered in this method; that is, the wavelength of reference.

\section{Conclusion}

The variability analyzed in the oligo-to-hypertrophic system represented by $\mathrm{Nav}$ and $\mathrm{BB}$, respectively, showed that higher TSI values implies in lower correlations between $b_{b p 440}$ and [TSM]. The TSI values are calculated based on [Chl-a], and the absorption feature of [Chl-a] in $440 \mathrm{~nm}$ affects the backscattering in this wavelength once the absorption mechanisms remove the available light within the system. Afterward, the same model agreement were not hold in both environments because [Chl-a] affected our results. Considering the available algorithms to estimate $b_{b p}$, quasi-analytical models also presented limitations, mainly in their empirical step that depends on the right choice of wavelengths that produce the lower errors to estimate the IOP. At this moment, the remote sensors available, which provide free data, do not have bands that perfectly match with those reported in literature,
Table 2 Steps of the QAA version 5 to obtain the $b_{b p}(\lambda)$

\begin{tabular}{llll}
\hline Steps & Property & Derivation & Approach \\
\hline 0 & $r_{r s}$ & $=R_{r s} /\left(0.52+1.7 R_{r s}\right)$ & Semi-analytical \\
1 & $u(\lambda) \equiv \frac{b_{b}(\lambda)}{a(\lambda)+b_{b}(\lambda)}$ & $=\frac{-0.089+\sqrt{0.089^{2}+4 \times 0.125 r_{r s}}}{2 \times 0.125}$ & Semi-analytical \\
2 & $a\left(\lambda_{0}\right), \lambda_{0}=555$ & $=a_{w}\left(\lambda_{0}\right)+10^{-1.146-1.366 \chi-0.469 \chi^{2}}$ & Empirical \\
3 & $b_{b \mathrm{p}}\left(\lambda_{0}\right)$ & $=\frac{u\left(\lambda_{0}\right) a\left(\lambda_{0}\right)}{1-u\left(\lambda_{0}\right)}-b_{b w}\left(\lambda_{0}\right)$ & Analytical \\
4 & $Y$ & $=2.0\left(1-1.2 \exp \left(-0.9 \frac{r_{r s}(443)}{r_{r s}\left(\lambda_{0}\right)}\right)\right)$ & Empirical \\
5 & $b_{b p}(\lambda)$ & $=b_{b p}\left(\lambda_{0}\right)\left(\frac{\lambda_{0}}{\lambda}\right)^{Y}$ & Semi-analytical \\
\hline
\end{tabular}


representing a challenge in our case and indicating that further studies have to investigate the wavelength choice to retrieve IOPs from satellite images in tropical inland waters.

\section{References}

Alcântara E, Watanabe F, Rodrigues T, Bernardo N, Rotta L, Carmo A, Curtarelli M, Imai N (2016) Field measurements of the backscattering coefficient in a cascading reservoir system: first results from Nova Avanhandava and Barra Bonita reservoirs (São Paulo, Brazil). Remote Sens Lett 7:417-426

Antoine D, Siegel DA, Kostadinov T et al (2011) Variability in optical particle backscattering in contrasting bio-optical oceanic regimes. Limnol Oceanogr 56:955-973

APHA (1998) Standard methods for the examination of water and wastewater, 20th edn. American Public Health Association (APHA), American Water Works Association (AWWA), Water Environmental Federation (WEF), Washington

Barbosa FAR, Padisák J, Espíndola ELG, Borics G, Rocha O (1999) The cascading reservoir continuum concept (CRCC) and its application to the River Tietê-basin, São Paulo State, Brazil. In: Tundisi JG, Straskraba M (eds) Theoretical reservoir ecology and its applications. International Institute of Ecology, Academy of Sciences and Backhuys Publishers, São Carlos, pp 425-437

Boss E, Pegau WS (2001) Relationship of light scattering at an angle in the backward direction to the backscattering coefficient. Appl Opt 40:5503-5507

Brewin RJW, Dall'Omo G, Hardman-Mountford NJ, Sathyendranath S (2012) Particle backscattering as a function of chlorophyll and phytoplankton size structure in the open-ocean. Opt Express 20:17632-17652

Bricaud A, Babin M, Morel A, Claustre H (1995) Variability in the chlorophyll-specific absorption coefficients of natural phytoplankton: analysis and parameterization. J Geophys Res Oceans 100:13321-13332

Burrough PA, Mcdonnell RA (1998) Principles of geographical information systems. Oxford University Press, New York, p 333

Carlson RE (1977) A trophic state index for lakes. Limnol Oceanogr 22:261-369

Golterman HL (ed) (1975) Physiological limnology. In: An approach to the physiology of lake ecosystems (Developments in Water Science), vol 2. Elsevier, Amsterdam, p 489

Gordon HR, Brown OB, Jacobs MM (1975) Computed relationships between the inherent and apparent optical properties of a flat homogeneous ocean. Appl Opt 14:2417-2427

Isaaks EH, Srivastava MR (1989) An introduction to applied geostatistics. Oxford University Press, New York, p 561

Lamparelli MC (2008) Graus de trofia em corpos d'água do Estado de São Paulo. PhD Thesis, University of São Paulo

Latha TP, Nagamani PV, Rao BS, Amarendra P, Rao KH, Choudhury SB, Dash SK, Sarma VVSS (2013) Particle backscattering variability in the coastal waters of Bay of Bengal: a case study along off Kakinada and Yanam regions. IEEE Geosci Remote Sens Lett 10:1517-1521

Le CF, Li YM, Zha Y, Sun DY (2009a) Specific absorption coefficient and the phytoplankton package effect in Lake Taihu, China. Hydrobiologia 619:27-37
Le CF, Li YM, Zha Y, Sun D, Yin B (2009b) Validation of a QuasiAnalytical Algorithm for highly turbid eutrophic water of Meiliang Bay in Taihu Lake, China. IEEE Trans Geosci Remote Sens 47:2492-2500

Lee Z, Huot Y (2014) On the non-closure of particle backscattering coefficient in oligotrophic oceans. Opt Express 22:29223-29233

Lee Z, Carder K, Arnone RA (2002) Deriving inherent optical properties from water color: a multiband quasi-analytical algorithm for optically deep waters. Appl Opt 41:5755-5772

Lobo F, Costa M, Philips S, Young E, McGregor C (2014) Light backscattering in turbid freshwater: a laboratory investigation. J Appl Remote Sens 8:083611

McKee D, Cunningham A (2006) Identification and characterisation of two optical water types in the Irish Sea from in situ inherent optical properties and seawater constituents. Estuar Coast Shelf Sci 68:305-316

Morel A (1974) Optical properties of pure water and pure sea water. In: Jerlov NG, Neilsen ES (eds) Optical aspects of oceanography. Academic, New York, pp 1-24

Padisák J, Barbosa FAR, Borbély G, Borics G, Chorus I, Espíndola ELG, Heinze R, Rocha O, Törökné AK, Vasas G (2000) Phytoplankton composition, biodiversity and a pilot survey of toxic cyanoprokaryotes in a large cascading reservoir system (Tietê basin, Brazil). Verh Internat Verein Limnol 27:2734-2742

Pak H, Beardsley J, George F et al (1970) Light-scattering vectors of some marine particles. Limnol Oceanogr 15:683-687

Shanmugam P, Sundarbalan B, Ahn YH, Ryu JH (2011) A new inversion model to retrieve the particulate backscattering in coastal oceans. IEEE Trans Geosci Remote Sens 49:2463-2475

Soares A, Mozeto AA (2006) Water Quality in the Tietê River Reservoirs (Billings, Barra Bonita, Bariri e Promissão, SPBrazil) and nutrient fluxes across the sediment-water interface (Barra Bonita). Acta Limnol Bras 18:247-266

Stramski D, Bricaud A, Morel A (2001) Modeling the inherent optical properties of the ocean based on the detailed composition of the planktonic community. Appl Opt 40:2929-2945

Stramski D, Boss E, Bogucki D, Voss KJ (2004) The role of seawater constituents in light backscattering in the ocean. Prog Oceanogr 61:27-56

Tiwari SP, Shanmugam P (2013) An optical model for deriving the spectral particulate backscattering coefficients in oceanic waters. Ocean Science 9:987-1001

Watanabe F (2016) Parameterization of bio-optical models for estimating chlorophyll-a concentration in a tropical eutrophic reservoir. $\mathrm{PhD}$ Thesis. Graduate Program in Cartographic Sciences. São Paulo State University, Campus of Presidente Prudente, São Paulo State, Brazil

Watanabe F, Alcântara EH, Rodrigues T, Imai NN, Barbosa C, Rotta L (2015) Estimation of chlorophyll-a concentration and the trophic state of the Barra Bonita hydroelectric reservoir using OLI/Landsat- 8 images. Int $\mathbf{J}$ Environ Res Public Health 12:10391-10417

WET Labs, Inc. (2013) Scattering meter (ECO-BB9) user's guide. Revision L. http://www.wetlabs.com/manuals

Wu G, Cui L, Duan H, Fei T, Liu Y (2011) Absorption and backscattering coefficients and their relations to water constituents of Poyang Lake, China. Appl Optics 50:6358-6368

Yang W, Matsushita B, Chen J, Yoshimura K, Fukushima T (2013) Retrieval of inherent optical properties for turbid inland waters from remote sensing reflectance. IEEE Trans Geosci Remote Sens 51:3761-3773 